\title{
Isolation in studio music teaching: The secret garden
}

\begin{abstract}
In comparison with classroom settings that are more accessible to the scrutiny of researchers and institutional monitoring, the one-to-one setting of instrumental and vocal studio teaching has been described as a "secret garden". The physical isolation of the music studio has deep roots within the traditions of apprenticeship and embodies aspects of conservatoire culture that are sometimes carried over into other musical styles. With a focus on higher education, this paper explores the nature and significance of isolation for the studio, alongside some of the benefits, limitations, and challenges that it offers. The authors contend that the physical disposition of the studio within the institution gives implicit support to the attitudes and assumptions that sustain traditional approaches to music performance teaching, and that making them explicit can help to open those approaches to further challenge, review and development.
\end{abstract}

\section{Keywords}

Music education, instrumental and vocal teaching, careers in music, one-to-one teaching, conservatoire, higher music education, higher education 


\section{Introduction}

Instrumental and vocal studio teaching is often characterised in terms of its isolated setting (see for example Bennett, 2012; Burwell, 2005; Carey et al., 2013a; Gaunt, 2008; McPhail, 2010; Mills, 2006; Reynolds and Beitler, 2007; West and Rostvall, 2003). Isolation is convenient, in that the music studio—-sealed, sound-proofed or placed at a distanceprovides practitioners with a quiet, dedicated and undisturbed space where they can cultivate fine aural discrimination and technical control. Isolating the studio also prevents it from impinging on the soundscape of other institutional activity. In addition to mutual convenience, however, the isolation of the studio has deep roots within the traditions of apprenticeship and embodies aspects of conservatoire culture. The traditions that are embedded in the experience of teachers and students, the history of musical performance training and the concrete setting may all serve to disguise and perpetuate assumptions, attitudes and practices in music studio teaching.

Musical performance is a specialist subject area in higher education, and it is often taken for granted that its combination of artistry and craftsmanship is best cultivated in studio lessons, where one-to-one attention allows the development of personalised content and a responsive structure (Schön, 1987). Historically, however, the isolation of the studio system has done little for the development of coherent pedagogies: the activity of the teacher-student dyad in each is inaccessible to others, and teachers are often obliged to develop their work in relative isolation, relying on reference points that are limited to their personal histories and accumulating experience. This might be related to a hierarchical structure in studio practices, with authority strongly invested in the teacher as representative of both the state and the history of the art (Burwell, 2012); it might be further related to perceptions of elitism, particularly in the traditions of classical music but also, to some extent, jazz (Krims, 2007). 
We should not assume, however, that practitioners have consciously chosen isolation, nor that an arrangement that seems convenient must be necessary or even desirable. The positions of studio teachers could be described not only as exclusive, but as excluded: isolation might embody perceived privileges but it can also represent a constraint on the development of professional identity and participation, at what might be experienced as either the periphery or the margins of the institution (Wenger, 1998). This paper explores the nature and significance of isolation in the studio, alongside some of the benefits, limitations, and challenges that it offers. It argues that the physical disposition of the studio within the institution gives implicit support to the attitudes and assumptions that sustain traditional approaches to music performance teaching, and that the isolation of those approaches inhibits what should be a productive flow of information about, and for, studio values and practices. The nature and consequences of isolation must be made explicit if they are to become objects for reflection, thus opening studio practices to further challenge, review and development.

\section{Metaphors for the isolated studio}

Many of the assumptions about music studio teaching are embedded in the metaphors used to discuss it, and it is worth examining these to see what might be learned about practices that are rarely articulated outside the privacy of the studio. In the research literature focused on studio-based instruction one of the most common metaphors is apprenticeship, and although references to it are rarely explained, close inspection reveals common assumptions about its meaning. These include the cultivation of artistry and craft skills, processes of modelling and participation, and social aspects of both the practice and performance of music (Burwell, 2013). Among these, modelling and participation can be linked with the isolation of the studio, where the student is presented with a single exemplar. Jørgensen (2000: 68) asserts that historically, "the master usually is looked at as a role model and a source of identification 
for the student, [while] the dominating mode of student learning is imitation”. This historical model, with the teacher apparently dominating a relatively passive student, has been illustrated in Manturzewska’s (1990: 135) survey of 165 professional musicians in Poland, whose own "master teachers" had dominated the development of their "personality, aesthetic attitudes, life philosophy, professional standards and attitudes toward his or her own artistic and professional activity and the role of musician in contemporary society”. Of course, the currency and generalisability of this model are limited, and as Nielsen (2006: 3) points out, apprenticeships can differ in their emphasis on the master as either the central figure, or one influence among many in a community of learners.

It is difficult to generalise, too, about the dominance of modelling and imitation within the studio. Institutions of higher music education provide a range of group-based activities from which a student might choose models; but the models presented in individual studio lessons are presumably closer and more immediate, and this makes it more difficult for maturing students to consciously choose the influences they adopt. The idea of imitation raises anxieties among music performance students, who can be embarrassed at the notion of copying their teachers (Nielsen, 2006: 9), particularly in terms of expression and interpretation, where individuality is highly valued. However, imitation can be viewed more positively. Its significance is contingent on what is being learned, and it may be useful and even indispensable, for example, in the acquisition of complex technical skills. In private consultations, the studio teacher can select and devise demonstrations that reflect the individual student's concerns across varying challenges and stages of development: HyryBeihammer (2010: 172) even describes teacher demonstration as “part of giving feedback”. 
Imitation can also be understood as a continuum between "a relatively passive process of direct copying, and a highly active conception of participation in a community of practice” (Burwell, 2013: 280). Thus Nerland and Hanken (2002: 168-169) assert that studio interactions afford "the opportunity to observe and participate in profession-related practices under the supervision of an experienced 'master' of the discipline, [providing students] with access to crucial knowledge and standards of the discipline”. Nielsen (2006: 4) concurs that the one-to-one setting gives students direct access to musical performance practice as represented by the master, and describes the teacher's own playing-in both public performance and in the privacy of the studio-in terms of mediating strategies, and transparency (Lave and Wenger, 1991). Similarly, Hyry-Beihammer (2010: 172), investigating the practice of an expert piano teacher in Finland, emphasises the transparency afforded within the studio setting which allows the teacher to make the processes behind musical performance "visible and audible” through guided demonstration and feedback.

Direct and individual access, in the private studio within a professional setting, can bring participants together in a relationship of "businesslike intimacy” (Burwell, 2012: 150; see also Nerland and Hanken, 2002; Presland, 2005). At the same time, of course, the walls that facilitate privilege of access for the individual student are what restrict access for others. Particularly in higher music education, where entry is often subject to audition, both teacher and student can occupy “exclusive” positions, selecting or seeking one another out (Nerland and Hanken, 2004: 3). Thus the sub-title of Hyry-Beihammer's (2010) study draws on a further metaphor for the studio, implying some tension between perspectives: "From secret garden to transparent modelling”. 
The sub-title of the current paper is taken from a case study conducted by Young, Burwell and Pickup (2003: 144), who sought "insights to the whole field of instrumental teaching which, it could be argued, has been something of a 'secret garden', especially compared with the scrutiny currently experienced by classroom teachers in schools”. The authors' reference evoked Frances Hodgson Burnett's The secret garden (1911), one of the canonical works of English children’s literature (Dinter, 2015). Burnett’s protagonist is Mary, a ten-year-old orphan who begins to visit and cultivate a walled garden where she feels "securely isolated, 'almost like being shut out of the world in some fairy place’” (222). In the novel, the garden becomes a metaphor for transformative and even therapeutic processes, setting Mary and some new friends on their paths toward maturity and social "normalization", "inextricably linked to their spatial practices” (223).

The analogy with the secret garden is potentially rich: Burnett's fictional characters develop both autonomy and a sense of identity through dedicated work, and the transformative potential of such a setting — like that of the music student granted the focused attention of a publicly recognised expert in the field, typically over an extended period—seems clear (Carey et al., 2013a). Young et al. (2003) offered no particular discussion about secrecy in the garden, but elsewhere in the literature, the link between isolation and secrecy has been made more explicit. Thus Carey et al. (2013b: 359), in a discussion of institutional development, suggest that one-to-one teaching takes place "behind closed doors in a culture of concealment”. Davidson and Jordan (2007: 730) assert that studio teaching is the only example of apprenticeship in which "secrecy of the craft” persists, to protect and consolidate skill and to “make the working practices seem more magical, and important”. MacGregor (2016: 336) agrees that historically, guilds were “almost secret societies”, with a restriction of membership to guarantee “quality, standards and, every bit as important, prices”. 
Again, however apt they may seem, the generalisability of these analogies-apprenticeship, or secret garden-must be limited, and an investigation of the degree to which secrecy has been deliberately adopted by studio practitioners would be difficult and unpromising. A teacher inducted into the studio tradition, relying on a limited range of reference points in developing her own work, and on her students' performance results to indirectly validate her own success, might well appear to be—or indeed become-secretive; but it would be unfair to evaluate her attitude without reference to the issues of access that will have done so much to shape it.

\section{Cultural implications of isolation}

The concrete setting of the studio has cultural implications that can be traced to the nineteenth century, when the studio apprenticeship system was embraced by the emerging conservatoires. Many modern-day institutions date from or refer to the values and assumptions of that time, and where a substantial element of studio teaching is retained, it is regarded as central in importance (Carey et al., 2013a; Gaunt, 2008; Presland, 2005): the “bedrock of higher music education” (Gaunt, 2013: 50-51). Arguably, the sense of purpose too has been retained, in the emphasis that such institutions tend to place on their public faces. Thus Kingsbury (1988: 34) notes that the administrative offices of an American conservatory are magnificently furnished in "shining evidence of a tradition of elegance”, and he describes the concert hall as a splendid focal point, with "an arched parquet ceiling and an expansive, handsome wooden concert stage”. Similarly Triantafyllaki (2010: 191) describes the concert hall of a Greek conservatoire with its "imposing, high, glass ceiling and solid stone columns”, representing the public front of the institution and making students’ performing activity highly visible. 
These architectural arrangements evoke cultural perceptions of "art music”, which Nettl (1995: 41) associates with “commercials for wine, stylish furniture, or expensive coffee”; and an underlying notion dating from the eighteenth century, that performers are by definition separated from others, typically on a raised platform (Frederickson and Rooney, 1990: 193). This dimension of isolation suggests hierarchy and elitism, analogous to the closed-off classical department of the modern "phonogram and video store”, described by Krims (2007: xiv): aside from sound-proofing, the physical isolation has a symbolic function in the “marking of classical music (and sometimes its fellow 'high’ music, jazz, along with it) as a specialized genre, one whose marketing, consumption, and appreciation require special conditions and an impermeable separation from other music”.

The relationship between the concert hall and the studio was forged in the late nineteenth century, in response to a changing market for music that demanded the production of more professional performers. A vivid contrast can be seen between the first building occupied by London’s Royal College of Music and the purpose-built premises of 1894: the first had a small number of studios and no hall, and was “more suggestive of a young ladies' finishing school” (Wright, 2005:262), while the later establishment had a large number of individual studios surrounding a public concert hall and supplying it with aspiring performers. Wright (2005: 262) describes the "masculine bulk" of the new building, which remains the centrepiece of the college, as a conscious projection of its professional purpose. Although twenty-first century conservatoires are again adapting their purposes in response to changes in the industry (for example, Renshaw, 2002; Gaunt, 2016), traditional attitudes are arguably embedded in the buildings themselves, with professional performance regarded as the underlying aim of studio learning. 
Of course, there is a good deal of variety among institutions, with local variants in name and meaning: the music institution might be known as a conservatoire (for example, in the UK), conservatory (USA), conservatorium (Australia) or academy (Norway), while universities offer music education through faculties, schools or departments. The scope for generalisation is further impeded by the relationships among institutions, with Australian conservatoria, for example, having amalgamated with traditional universities in the late $20^{\text {th }}$ century. One-toone studio teaching is most likely to be included in dedicated institutions and those focused on the tradition of classical music, but many conservatoires-all of those in the UK, for example-include jazz as well as classical music; popular music performance is more likely to be studied in "new” universities (Cloonan and Husteldt, 2012), but is gaining acceptance in conservatoires (Carfoot et al., 2014).

Notions of hierarchy remain: Dyndahl et al. (2016) describe the “cultural omnivorousness” and "gentrification” through which Norwegian higher music education has gradually embraced a wider range of musical styles, noting that jazz and "high" popular culture have been earlier and more eagerly included than those associated with working class culture, such as country music, blues, rock and roll, and punk rock. Processes of inclusion have begun in academic study, prior to the inclusion of courses in practical performance (Dyndahl et al., 2016: 14). Where performance programmes are extended to more popular styles, new modes of delivery are sometimes devised to suit their pre-existing traditions, using collaborative and peer learning to complement or replace one-to-one studio tuition (Carfoot et al., 2014; Weston, 2017a). However, in many of the leading institutions in this field-including the Liverpool Institute of Popular Music, the University of Salford, and the Institute of Contemporary Music Performance — the provision of studio tuition appears as a mark of prestige; the international reputation of the Berklee School of Music rests on the high 
standard of individualised instrumental tuition in its contemporary music programs (Weston, 2017b).

The culturally mediated use of space that positions the studio in relation to the performance hall, and the performer in relation to the critical audience, may be reflected in studio lesson behaviour, particularly when professional performance is the vocational aim of lessons. Popular music is loosely categorised in terms of content and nomenclature (Cloonan and Husteldt, 2012; Weston, 2017a), and institutions that offer popular music programmes are far less likely than conservatoires to emphasise solo performance, but in the institutions mentioned above, studio tuition is associated with an explicit aim of reaching professional levels of competence, just as there is in specialist conservatoire programmes. Accordingly, spatial behaviour within the studio may be configured to invoke discourses of performance: Nerland (2001), for example, describes her observations of a studio teacher-himself a renowned concert soloist—who framed lessons as simulated performances, positioning himself as critical audience by sitting five metres away from the student. That the vocational aim might alter the approach to teaching and learning is shown in a second example from Nerland, in which the teacher invoked a discourse of ensemble playing by sitting beside the student so that they could work through more collaborative procedures (Nerland, 2001, 2007).

In terms of discourse analysis, the spatial dispositions of teacher and student in both of the cases described by Nerland reflect disciplinary strategies, procedures and behaviours through which the students come to "know their places" (Bălan, 2010: 59); in terms of power relations, as proposed by Foucault, students presumably carry their lesson activity back to the still-more isolated setting of the practice studio, just as prisoners subject to intense 
monitoring will learn to behave "as if the oppressor were always present” (Bălan, 2010: 60). This language suggests that the studio setting may expose the student to the mercies of a dominating teacher, and indeed the research literature includes occasional references to studio teachers who were “'tyrannical’, 'authoritarian’ and 'Svengali like’” (Hayes et al. 2003: 9). In such cases the studio might be seen to shield from view and even encourage the development of inappropriate behaviour from teachers. However, studio behaviour cannot be regarded merely as a matter of individual personalities, nor culturally endowed traits as something that can be simply laid down, by either teachers or students (Burwell, 2012). The cases described by Nerland (2001) embody assumptions about cultural aims and values that might be driven by the student as much as the teacher, and Nerland is careful to note that the two approaches are regarded as successful by the participants themselves. The approaches are not presented as polarities, nor evaluated by the researcher; discourse analysis seeks, rather, to identify the assumptions on which cultural practices rest, particularly when they may be "familiar, unchallenged and unconsidered” (Foucault, 1988: 154).

There are other ways in which cultural assumptions might be silently endorsed in the use of studio space, emphasising hierarchy or camaraderie and symbolising the status of the teacher and the degree of formality involved (Argyle, 1994). Insofar as it can be seen as his or her private territory, the studio setting can give the teacher control of the space and of the interaction, and this can be reinforced by the display of plaques, elegant furniture and other “territorial markers” (Burgoon and Dunbar, 2006). Despite this, the lines of demarcation are sometimes blurred among those admitted to the studio, with teachers seeing themselves as “eternal students and scholars” (Nettl, 1995: 45) while senior students may be functioning already in the professional field (Kingsbury, 1988: 19). Nettl (1995: 46) asserts that in music, "the association of teacher and student [is] closer than that found in higher education at 
large”, while the studio and the administration are farther apart. Similarly, Kingsbury (1988:

57) describes a tendency for students to align themselves with studio teachers more than other social configurations in the institution, as if allegiance to either the dean's office or the orchestra podium would "undermine the strength of the 'studio' social organization in the conservatory, the primacy of the artistic individuality of the faculty members, and in turn the aural tradition of musical performance that these faculty members serve to maintain”.

In the physical dispositions of purpose-built conservatoires, then, aspects of social practiceimplicating the status and purpose of studio work, as well as behaviour within one-to-one lessons - might seem to be set in concrete, just as so many of our civic buildings refer to the architecture of ancient Greece, and by extension to notions of democracy. In both, the purpose of the original design may be vaguely felt but difficult to deny, regardless of the diversity among contemporary institutions and cultures; and the isolation of the studio does nothing to support the critical appraisal and replenishment of its current fitness for purpose.

\section{Pedagogical implications of isolation}

It would be simplistic to argue that there is a single tradition of studio pedagogy, and in recent generations the extension of studio instruction to a wider range of musical genres presumably has broadened the range of approaches taken to teaching and learning, though these are more likely to be evident in the provision of group activity than within the secret garden of the studio. Even so, the physical disposition of the existing establishments, with roots in the nineteenth-century conservatoire culture, must have pedagogical implications for studio practices. The role of architecture in educational spaces is associated with what Shulman (2005: 53) calls "signature pedagogies" that reflect the distinct values and practices of professions in, for example, the law school, the engineering lecture, the design studio, and 
clinical rounds. This concept may be recognised in music studio teaching easily enough, with some qualifications. For example, Shulman argues that in these subject areas, student "performance" is made public, and that the exposure reduces "the most significant impediments to learning in higher education: passivity, invisibility, anonymity, and lack of accountability” (56). Concert performance might seem to be a sparkling example of this, but it should be remembered that only a minority of undergraduate musicians achieve sustained exposure in public concerts, and that the isolated studio, where a good deal more of their time is spent, is a setting that actually highlights those impediments to learning. The studio door renders the collaboration of teacher and student invisible to others; the closed setting may heighten the student's accountability to the teacher, but reduce teacher's accountability to the institution; and the potential for the teacher to dominate lesson interactions, if not through personal intentions then through cultural assumptions, might keep the student relatively passive.

If the isolation of the studio is part of the signature pedagogy of music education, then the distinction among spaces is matched by a distinction among practices. Triantafyllaki (2010: 191) describes a university music department in which performers and "theoreticians” occupy distinct spaces, ostensibly to respect the quiet wanted by musicologists; and in European conservatoires, musical theory and practice have been described as “dislocated areas” (AEC, 2015: 27). The Association of European Conservatoires (2007: 5), on the strength of "the largest European project on professional music training to date”, urges the development of more holistically conceived curricula:

[M] ost of the time we... think of the Principal Study [studio] lesson as one type of learning, sitting in its own compartment, and the aural class as another-and so on through all the traditional divisions of the curriculum. ... [T]he student packs away 
these ideas along with his or her notes and goes on to an instrumental lesson in which they perform the piece they have prepared thinking only of technique and tone production. ... [T]his kind of dislocation between types of learning can be surprisingly common and is almost always damaging to a student's development as a thoughtful and well-rounded musician. (AEC, 2007: 12-13)

The dislocation among subject areas and the focus within the studio on technique and tone production might be associated with the development or adoption of routines within the signature pedagogy. Shulman (2005: 56) explains that routines can simplify the complex challenges of professional education, "because once they are learned and internalized, we don't have to think about them; we can think with them” (emphasis added). Although routine may be valuable and even indispensable in such settings, it must involve constraint as well as opportunity, recalling Foucault’s (1988: 154) reference to “familiar, unchallenged and unconsidered” cultural practices. Thus the AEC (2007: 12) admits that the divided and distinct routines among subject areas "have come about for good reasons, of course", but maintains that they are not essential, and should not be allowed to foster similar divisions in the minds of practitioners.

Similarly, an unquestioned emphasis on performance as a separate activity may remain influential in the minds of music graduates who become teachers. This is highlighted by Bauer and Berg (2001: 63), whose survey of 120 graduates found that their own teaching was focused “on 'getting ready for the next performance' rather than 'music education through performance' and other musical activities” (emphasis added). In this study, instrumental teachers rated the model presented by their own previous teachers—conductors as well as “applied” music instructors_-as more influential than their education courses: Bauer and 
Berg (2001: 62) suggest that the visibility of performing teachers lent them more credibility than their education lecturers. Their findings suggest a tendency for graduate teachers to develop their approach to pedagogy with reference to previous masters, whose work they have experienced in practical settings, drawing on relatively discrete historical or "vertical" traditions more than the "horizontal" provision of shared coursework.

This impression is supported by an interview study conducted by Baker (2006: 44) in which school-based instrumental music teachers tended to regard their undergraduate qualifications as "an inadequate platform for their professional lives"; even the minority who had undertaken formal teacher training regarded that as “meagre preparation”. It remains common for undergraduate musicians to major in performance on the assumption that their performance skills will be adequate to support future teaching, though often there has been little choice: Cathcart (2013: 53), in an historical survey of piano teaching in the UK, remarks that "it took until almost the end of the [twentieth] century for teacher training for instrumental teachers to become available”. Even now, Bennett (2012: 54) argues that providers of such training face "myriad limitations”, including ... low status; low contact hours; lack of alignment with other elements of the curriculum (including the methods courses available to education majors); and the capacity to organise school- or studio-based experience, in turn limited by staff and student time, student motivation ... course structure, and the absence of the pedagogical knowledge required by students to access a formal practicum. Although an increasing number of institutions now offer programmes of study that are focused on studio pedagogy, it remains more common for studio teacher training to be positioned as an optional inclusion in undergraduate programmes focused on musical 
performance, thus reinforcing socially and culturally prescribed perceptions of teaching as a second best or fall-back career choice.

Ironically, studio teachers in higher education —-themselves models for undergraduate musicians, in terms of both performance and teaching-are unlikely to have had formal teacher training (Gaunt, 2013). Purser (2005: 287) asserts that conservatoire teachers are often appointed because of their status as performers, and that "playing [is] the major factor in making an appointment”. Shulman's (2005) account of professional education indicates that it is by no means uncommon in higher education for faculty members to have no direct preparation for teaching, instead modelling their work on the teaching they received. Persson (1994: 223) has described such approaches as “commonsense”, but for Shulman (2005: 57) they entail a more deliberate ““apprenticeship of observation’ [which] is powerful even among precollegiate teachers who do undertake pedagogical training”. This suggests an active and purposeful development of knowledge and skill, leading Mills and Smith (2003: 21) to dismiss the "anecdotal assertion that instrumental teachers simply teach as they were taught” (emphasis added).

Over the past fifteen years, music scholars have amassed data about more or less reflective and responsible processes from practitioners ranging from undergraduate musicians through to conservatoire professors (Haddon, 2009; Mills, 2004a, 2004b; Mills and Smith, 2003). However, it seems that many institutions of higher education - taking for granted that the high level of performance expertise among staff is sufficient to ensure excellence in teaching — have done little to support the professional development of studio teachers, or to facilitate collaboration among them. This is confirmed by Purser (2005: 297), who interviewed six UK conservatoire teachers about influences on their teaching. Purser reported 
that although the teachers had been able to develop their work with reference to their own conservatoire teachers, alongside experience and reflection, these were "people working in professional isolation” with limited opportunities to “exchange information (or knowledge, or wisdom)”. Triantafyllaki (2010: 197) reinforces this view, arguing that institutions should provide studio teachers with "the space, time and resources to explore and reflect on their professional practice as it develops both within and beyond their educational workplace”. Although Purser (2005: 298) concedes that peer observation schemes are becoming more common in conservatoires, he notes that students’ performance achievements remain more visible than studio practices, and although he would not want to homogenise those practices "it is hard not to draw the conclusion that some forum for sharing experience and modes of good teaching practice would be beneficial”.

\section{Psychosocial implications of isolation}

The call for a more systematic provision of opportunities for studio teachers to meet may be complicated by the affective aspects of engaging with professional development. Thus, for example, Purser (2005: 297) notes with some surprise that conservatoire studio teachers can be "nervous about airing in public (amongst peers) what [has] been developed in private (with students)", and the teachers he interviewed gave “a universal and emphatic 'no' to the suggestion that they might participate in a seminar exploring teaching practice” (296). This might be related to the teachers' view of their standing in the profession, and an assumption tied to their status as performers that if there is professional development activity, they should be leading it (Burwell, 2012: 122; Purser, 2005, 297).

Perhaps studio teachers in higher music education are more or less self-conscious about the assumption that their performing expertise will be sufficient to guarantee or compensate for 
undetermined levels of teaching ability and experience. Forced to develop their teaching in isolation, they may feel apprehensive about whether their approaches will be well received, or defensive about being asked to account for them: indeed, they may not possess the pedagogical language that would enable them to articulate their practices. Purser (2005: 296) reports that for the conservatoire teachers he interviewed, "the thought of sharing the techniques which they have developed privately, often over a period of many years, in the intimacy (one referred to it as the 'secret trade') of one-to-one teaching was simply intimidating”. Morrison (in GSMD, 2016: 36), discussing the background to recent PD activity in another UK conservatoire, explains further:

With individual development and self-assessment largely being done independently without external feedback, feelings of insecurity have easily arisen about decisions being taken as a teacher and about the impact, or lack of impact, of the teaching interactions. Such insecurity and vulnerability seem to exist for our protagonists because of the lack of context they have for their own approach in relation to formal structures, and therefore a strong reliance they have on feelings and intuition in making pedagogical decisions.

Personal and professional contact among studio teachers can help to overcome such feelings of insecurity, but the opportunity for teachers to meet both formally and informally is again limited by the isolation inherent in studio teaching: according to Finnish teacher-educators interviewed by Juntanen (2014: 16), “the biggest obstacle to collaboration amongst colleagues [is] having so many part-time teachers” who, engaged for only a few hours a week, rarely attend meetings and developmental work. Triantafyllaki (2010: 191) points out that not all institutions provide studio teachers with "common rooms such as a staff room, cafeteria or a visitors'/seating area”, and Spencer (2015: 70) adds that issues of access can be 
extended to parking spaces, office facilities, and the institution's internal internet sites. A lack of common spaces forces participants to construct their professional identities elsewhere, through lessons, performance activity and institutional documentation, and for the university studio teachers interviewed by Spencer, those identities are characterised by neglect, exclusion, powerlessness and resignation (100).

Students too construct aspects of their identities within the studio, where the dominant model of their own studio teachers, perhaps reinforcing the stereotypical image of the artist as isolated genius, can strengthen the tendency for student musicians to identify as performers rather than teachers (Baker, 2006). Their identity formation does not begin in higher education, of course, and music education majors, for example, often enter "with fantasized notions of teacher derived from film, television, books [as well as] their own lived experience” (Bennett, 2012: 55). Isbell’s (2015) review of music education research reports that "students enter their preparation programs with strong preconceived notions of what and how to teach [in] music ... [while the institution may continue to favour] the establishment of an artist identity over a teacher identity”. Mills (2006) agrees that musicians find it particularly difficult to become socialised as teachers when their education is conducted separately, and Froehlich (2002), characterising the differences between schools of music and colleges of education, draws a contrast between artistic and competitive attitudes in the first, and sharing and teamwork in the second.

Undergraduate music students come to realise that performance-based careers are an unlikely outcome of their training, but when their role models are successful performers "there is a very real risk that students’ performance identities [will] preclude them from planning a positive engagement with non-performance activities” (Bennett, 2009: 313). The contrast 
between student expectations and the reality of careers in music suggests that many graduates must face a difficult transition, implicating motivation and self-esteem as well as professional issues. Those who go on to become instrumental teachers in school settings are likely to be distanced from the support of non-musical colleagues because of the geographical location of music facilities, and by the likelihood that will be the only teachers of their specialist subject in their school (Bell-Robertson, 2014).

With the isolation of their specialist subject projected as “a geographical fact” (Krims, 2007: $\mathrm{xv})$, instrumental teachers might feel a lack of social and emotional, as well as cultural and professional, support. This is borne out in the experiences of novice teachers who participated in an online community established by Bell-Robertson (2014: 446), and who used that to focus on the affective aspects of their professional lives more than curriculum or pedagogy. The practice of sharing thoughts, feelings, and day-to-day occurrences in the virtual space helped the teachers cope with their questions and struggles by helping them know they were not alone, giving them a forum to talk about unique needs and topics, and contributing to a sense of altruism and feeling helpful when they could assist a peer in a similar circumstance.

Emotionally supportive networks such as these might be linked to "communities of coping", not least because these have been characterised in terms of service industries where there is little task interdependence among workers, so that workers are often isolated in dealing with clients (Korczynski, 2003). It is interesting to note that "coping” implicates negative emotions, in contrast to "community”- “a 'warmly persuasive word' that 'never seems to be used unfavourably’” (Williams, in Tight, 2015: 114), and Korczynski (2003) points out that communities of coping can represent an element of resistance to management. Studio practitioners — whether teachers or students_-are members of multiple communities of 
practice, which include their formal engagement as well as informal liaisons among themselves, external as well as institutional enterprises; and aside from the tensions of multimembership among these, insufficient opportunities for inclusion can lead to attitudes of compliance more than participation (Wenger, 1998: 187).

\section{Benefits, limitations and challenges}

Although the isolation of the music studio is associated with psychological and social challenges, these can be balanced by the powerful benefits of the master-apprentice relationship fostered within the studio. This may be true of other instances of apprenticeship, but the subject matter of musical performance "seems more personal, moral, and emotional than professional or economic” (Kingsbury, 1988: 19-20), and this can make the relationship more intense. As Nerland and Hanken (2002:180) explain, “working with the music implies that both student and teacher must expose themselves emotionally, and therefore they grow closer to each other on a personal level”. Conversely, of course, this emphasis on the personal aspects of a professional relationship might become problematic. Indeed, being allocated to an isolated teacher-student dyad over an extended period may well exacerbate any problems, particularly if students are reluctant to discuss them (Gaunt, 2008; Hanken, 2011). Despite such challenges, the studio teacher is potentially and ideally a powerful motivating force for the student (Uzler, 1992).

A further benefit of studio teaching is the scope it allows for tailoring a personalised course of study that is aligned with the individual strengths and interests of the student: course requirements are typically broad, giving the teacher a high degree of autonomy in identifying technical areas for development and helping the student to choose suitable repertoire. There is of course a danger that the teacher's autonomy in the studio may encroach on the 
development of the student's own. Reinhert (2017), in a professional blog discussing the provision of studio tuition in popular music courses, characterises a worst-case scenario where students have “no awareness of what they're doing or why they're doing it other than they were told to do it”; but she also argues that a group vocal lesson is like a group doctor's appointment, “[w]here everyone in the room has a different and distinct challenge to overcome". The reference to doctors provides a useful clue to the negotiation between teacher authority and student independence: the principles of organisational coaching hold that the client or student is not ill, and "has not come to be fixed" (Rogers, 2016: 7; original emphasis), but coaching is only part of the studio teacher's role, and the approach taken will depend on the matter at hand. In terms of instrumental technique, for example, there may well be problems that need to be "fixed" through direct instruction from the teacher.

It is difficult to know how often there are clashes of views about the approaches to teaching and learning within the studio, but there is evidence suggesting that there is a lack of a shared vision for practice, even among teachers. The teachers interviewed by Mills (2004b) and Juntanen (2014) regarded themselves as lifelong learners who were engaged in constant selfdevelopment, but they regarded their visions of teaching as personal, with no clear agreement among them except to agree that there was no shared vision (Juntanen, 2014). Presumably professional organizations could help to overcome the limitations of isolation by fostering interaction among teachers, but the literature reports mixed attitudes toward them. In Cathcart's (2013) survey of UK piano teachers, only 15\% referred to the positive impact of professional development courses, and teachers without formal qualifications in music—as distinct from music education, for example-were significantly more likely to attend courses than music graduates. The apparent lack of interest from music graduates perhaps recalls Isbell's (2015) remark that the primary socialisation of teachers can have a lingering effect on 
their identity, suggesting a higher regard for performance and a predilection for developing their teaching practices in isolation.

In recent years, institutions of higher education have adopted a range of initiatives designed to meet the challenges posed by the multifaceted isolation of studio practice, for both current and future practitioners. Pathways focused on studio pedagogy are becoming more widely available for undergraduates (for example at the University of New South Wales, and Queensland Conservatorium Griffith University, Australia) and postgraduates (for example, Royal Northern College of Music, UK). Practitioners who are engaged already with musical careers may appreciate the flexibility of online alternatives offered for performing arts education or tertiary teaching (for example, Curtin University, Australia). In the context of teachers' communities of practice, Jones (2010) has demonstrated that institution-led teaching fellowships focused on pedagogic research can raise the status of teaching, inform curriculum development, affect attitudes to innovation, develop professional and research expertise, and contribute to shared knowledge. In another example, Zelm (2013: 181) reports on an opportunity for teachers to participate in curriculum development at the Royal Conservatory of The Hague, with teachers designing and implementing a course based on peer learning for students, and thereby beginning "to practice exactly those skills that we wanted to develop with our students”. At the Norwegian Academy of Music, individual teachers are invited to design, lead and share projects focused on better ways to support students' personal practice, with the explicit aim of shifting perspectives about practice and an implicit aim of opening teacher attitudes to innovation, collaboration and research (Jørgensen, 2015). Similarly, the Guildhall School of Music and Drama offers a programme of mentoring and coaching for the benefit not only of students but of teaching and administrative staff (GSMD, 2015), and the Innovative Conservatoire (ICON) group conducts 
seminars and workshops across the UK, Europe and Australia that are "designed to catalyse collaborative reflection at an international level” (Gaunt, 2013: 49).

These initiatives often refer to communities of practice (Wenger, 1998), a term that has become "ubiquitous in the literature of teaching and learning in higher education" (Lea, 2005: 186). Cox (2005: 527) argues that its "reusability" is due to inherent ambiguities that allow it to be appropriated for different purposes, and it can be used as either a heuristic for understanding aspects of learning, or the more practical purpose of establishing more or less formal groupings of learners, particularly within organisations or on line. Both usages are relevant in this discussion of the isolation of studio teaching in higher music education. The first is most closely related to situated learning as characterised by Lave and Wenger (1991), in that it explores learning as a process of socialisation: this includes aspects of the apprenticeship in which the master serves as role-model, with an area of influence that extends beyond instrumental or vocal technique and interpretation; the adoption of attitudes toward the prestige of performance and the salience of the concert hall relative to the isolated studio; and the distinct positioning of each element of music education, that tends to separate studio work from group practice and academic activity. In terms of reification, as characterised by Wenger (1998), the crystallisation of the subject into these separate elements leaves teachers and students with the problem of transforming inert theory back into a practical skill (Burwell, 2012: 16).

The socialisation of studio practitioners is also affected by the disposition of physical spaces that has left them to develop their work in relative isolation. Insofar as practices evolve as shared histories of learning (Wenger, 1998: 87), it must be significant that music studio teachers have had so few opportunities to share their ideas and developing skills, either 
through training that might have prepared them for their specialist field or through workplace contact with one another and with the institution that houses them. If the institution can be considered a community, we should beware of that word evoking "[simply] a rather large, helpful and friendly, bounded group” (Cox, 2005: 532): the fact that some members are unable to fully participate points to issues of "power and authority, and how contestation over meaning is played out in institutional settings” (Lea, 2005: 185-186). Wenger (1998: 164) concludes that "[i]n other words, non-participation is, in a reverse kind of fashion, as much as source of identity as participation”.

In recent literature, “community of practice” is more commonly applied to the design and support of learning networks, often established by or with assistance from an institution (Cox, 2005; Lea, 2005). The efforts of institutions described above-supporting teaching fellowships, encouraging a contribution from studio teachers to curriculum design and research, and opening spaces for collaborative reflection—resonate with Wenger’s (1998: 249) recommendations that practitioners should be engaged in the design of their practice, and have the resources "to negotiate their connections with other practices and their relation with the organization”. The need for the development of shared values is emphasised by Vescio et al. (2008) in their review of research into professional learning communities (PLCs) in American schools; other common characteristics include a focus on student learning rather than teaching, reflective dialogue, the de-privatisation of practice, and collaboration. Importantly perhaps, PLCs are positioned as an alternative to the notion of providing knowledge that is generated by researchers outside the setting. As Cain (2015: 489) notes, "there is very little empirical evidence that educational research can inform practice in any direct way”, not least because of the personal, practical and value-laden nature of pedagogical knowledge. If research cannot inform practice directly, however, it can suggest a 
wider range of possibilities for future action and decisions: "not by discovering and dispensing facts, but rather by helping us better understand problems and their significance for action” (Bowman, 2005, 162). Considered in this way, the interface between current research and studio practice would seem to be an exciting and important area for exploration.

\section{Concluding remarks}

One-to-one music studio tuition is a problematic privilege. While practitioners in the conservatoire tradition hold that it is the optimal setting for the cultivation of advanced individual skills in technique and interpretation—a view often espoused in other musical styles and traditions - the isolation that frames studio practices can too easily set hard and opaque. The masters who become role models looming large in the isolated setting of the studio are unlikely to have had specialist training in instrumental or vocal pedagogy, and too often lack access to the communities of practice that might help them to develop their engagement—with pedagogy, with one another, and with the institution to which they contribute. If they sometimes seem reluctant, defensive, or even secretive in sharing their practices, the sources of identity formation that have been available to them-exclusive or excluded, peripheral or marginal—are often embedded in concrete institutional settings, and the cultural implications that come with them. Their presence may be little felt in the groupbased performance and academic activity of the institution, but the transparency of their authority in the studio offers powerful models to their students, and the students in turn tend to focus on their performance identities, overlooking the problems of isolation and persisting in the assumption that teaching expertise will be a by-product of their own performance skill. The cloistered cycle is complete when apprentices themselves become masters, expecting to discover their teaching skills in relative isolation. In twenty-first century higher education, cloistered cycles have no place. 
In fact, students have many opportunities for participating in a wider range of educational, musical activity, including lectures and seminars, masterclasses and workshops, ensemble rehearsals and increasingly, pedagogy classes. Even in the practical study of performance, many institutions have been turning to group-based activity, with collaborative and peer learning becoming more important particularly for popular music styles; in classical music, students sometimes move among several studio teachers, or have masterclass exposure to approaches that may complement or challenge their own teachers' approaches. There is perhaps an anxiety among practitioners that the provision of other modes of learning might be driven by considerations of funding as much as pedagogy (Carfoot et al., 2014; Lea, 2005; Reinhert, 2017), but the value of studio practices will not be demonstrated without opening them to scrutiny, negotiation and responsiveness to the evolving professional world. Institutional policy makers will need to ensure or be assured that studio practitioners are not so inflexible as the concrete settings might suggest, and this will require action from both.

Currently, students have more opportunity to meet, share and collaborate than their studio teachers, and institutions should take responsibility for opening the spaces needed for teachers to optimise their own participation in its communities of practice. Funding is again a consideration, and institutions do not always give priority to the financial support of professional development activity, particularly of peripheral members (Spencer, 2015: 77). For private and hourly-paid teachers, a desire to attend PD events has to be balanced against the cost of taking time out from paid work, and activities scheduled outside of normal business hours often occur at the very time in which many studio teachers are working. This is a challenge that must be overcome: digital technologies will prove invaluable in providing information and points of contact among studio teachers, and annual events can help to keep 
them appraised of evolving course requirements and assessment procedures—not to mention the evolving nature of higher education, and its relationship with the broader cultural industries.

In the development of pedagogical and scholarly expertise, funding constraints are no excuse for inaction: this is a shared challenge that can be resolved through collaboration. Support for the continual development of teaching skills can come merely from bringing teachers together, taking advantage of their declared propensity for lifelong learning; but increasingly, specialist research can give teachers much food for thought, encouraging them to approach their work "more intelligently, more imaginatively, more creatively, [and] more flexibly" by raising more cogent questions, with more provisional answers (Bowman, 2005, 162). While we can envision the development of communities of practice to address the isolation of studio teaching, with the support of flexible and sympathetic research, such developments will have to be driven by the needs, interests and arguably unique situations of their members.

\section{References}

Argyle M (1975, 2004) Bodily communication (2 ${ }^{\text {nd }}$ edn). London, New York: Routledge. Association of European Conservatoires (AEC) (2015) Perspectives on $2^{\text {nd }}$ cycle programmes in higher music education. Utrecht: Association of European Conservatoires.

Baker D (2006) Life histories of music service teachers: The past in inductees’ present. British Journal of Music Education 23(1): 39-50.

Bălan S (2010) M. Foucault’s view on power relations. Cogito 2(2): 55-61.

Bauer WI and Berg MH (2001) Influences on instrumental teaching. Bulletin of the Council for Research in Music Education 150: 53-66.

Bell-Robertson CG (2014) “Staying on our feet”: Novice music teachers’ sharing of emotions and experiences within an online community. Journal of Research in Music Education 6(4): 431-451. 
Bennett D (2009) Academy and the real world: Developing realistic notions of career in the performing arts. Arts and Humanities in Higher Education 8(3): 309-327.

Bennett D (2012) The use of learner-generated drawings in the development of music students' teacher identities. International Journal of Music Education 31(1): 53-67.

Bowman W (2005) More inquiring minds, more cogent questions: The need to theorize music education - and its research. Music Education Research 7(2): 153-168.

Burgoon JK and Dunbar NE (2006) Nonverbal expressions of dominance and power in human relationships. In The SAGE Handbook of Nonverbal Communication. SAGE Publications.

Burwell K (2012) Studio-Based Instrumental Learning. Farnham: Ashgate.

Burwell K (2013) Apprenticeship in music: A contextual study for instrumental teaching and learning. International Journal of Music Education 31(3): 276-291.

Cain T (2015) Teachers’ engagement with published research: addressing the knowledge problem. The Curriculum Journal 26(3): 488-509.

Carey GM, Bridgstock R, Taylor P, McWilliam E and Grant C (2013a) Characterising oneto-one conservatoire teaching: Some implications of a quantitative analysis. Music Education Research 15(3): 357-368.

Carey G, Grant C, McWilliam E and Taylor P (2013b) One-to-one pedagogy: Developing a protocol for illuminating the nature of teaching in the conservatoire. International Journal of Music Education 31(2): 148-159.

Carfoot G, Millard B, Bennett S and Allan C (2014) Parallel, series and integrated. Models of tertiary popular music education. In Smith GD, Moir Z, Brennan M, Rambarran S and Kirkman P (eds) The Routledge Research Companion to Popular Music Education.

Cathcart S (2013) The UK piano teacher in the twenty-first century. Exploring common practices, expertise, values, attitudes and motivation to teach. $\mathrm{PhD}$ thesis, Institute of Education, University of London, UK.

Cloonan, M and Husteldt, L (2012) Taking notes. Mapping and teaching popular music in higher education. York: Higher Education Academy, Arts and Humanities.

Cox, A (2005) What are communities of practice? A comparative review of four seminal works. Journal of Information Science 31(6): 527-540.

Davidson JW, and Jordan N (2007) "Private teaching, private learning”: An exploration of music instrument learning in the private studio, junior and senior conservatoires. In Bresler, L (ed.) International handbook of research in arts education Volume 1. Dordrecht: Springer, pp.729-744. 
Dinter S (2015) Spatial inscriptions of childhood: Transformations of the Victorian garden in The secret garden, Tom's midnight garden, and The poison garden. Children's Literature Association Quarterly 40(3): 217-237.

Dyndahl P, Karlsen S, Nielsen SG and Skåberg O (2016) The academisation of popular music in higher music education: the case of Norway. Music Education Research.

Foucault M (1988) Politics, philosophy, culture. Interviews and other writings 1977-1984. New York, London: Routledge.

Frederickson J and Rooney JF (1990) How the music occupation failed to become a profession. International Review of the Aesthetics and Sociology of Music 21(2): 189-206.

Froehlich H (2002) Thoughts on schools of music and colleges of education as places of "rites and rituals": Consequences for research on practicing. In Hanken IM, Nielsen SG and Nerland M (eds), Research in and for higher education. Oslo: Norges musikkhøgskole, pp.149-165.

Gaunt H (2008) One-to-one tuition in a conservatoire: The perceptions of instrumental and vocal teachers. Psychology of Music 36(2): 215-245.

Gaunt H (2013) Promoting professional and paradigm reflection amongst conservatoire teachers in an international community. In Westerlund $\mathrm{H}$ and Gaunt $\mathrm{H}$ (eds), Collaborative learning in higher music education: Why what and how? New York, NY: Taylor and Francis, pp.49-61.

Gaunt H (2016) Introduction to special issue on the reflective conservatoire. Arts and Humanities in Higher Education 15(3-4): 269-275.

Guildhall School of Music and Drama (GSMD) (2016) Empowering artists of the future through a transformational feedback model. York: Higher Education Academy. Available at: www.gsmd.ac.uk/transformationalfeedback (accessed 20 July 2016).

Haddon E (2009) Instrumental and vocal teaching: How do music students learn to teach? British Journal of Music Education 26(1): 57-70.

Hanken IM (2011) Student evaluation of teaching from the actors’ perspective. Quality in Higher Education 17(2): 245-256.

Hays T, Minichiello V and Wright P (2000) Mentorship: The meaning of the relationship for musicians. Research Studies in Music Education 15, 3-14

Hyry-Beihammer EK (2010) Master-apprentice relation in music teaching. From a secret garden to transparent modelling. Nordic Research in Music Education Yearbook 12, 161178. 
Isbell DS (2015) The socialization of music teachers: A review of the literature. Update 34(1): 5-12.

Jones J (2010) Building pedagogic excellence: Learning and teaching fellowships within communities of practice at the University of Brighton. Innovations in Education and Teaching International 47(3): 271-282.

Jørgensen H (2000) Student learning in higher instrumental education: Who is responsible? British Journal of Music Education 17(1): 67-77.

Jørgensen H (Ed) (2015) Teaching about practising. Oslo: Norwegian Academy of Music. Juntunen M-L (2014) Teacher educators’ visions of pedagogical training within instrumental higher music education. A case in Finland. British Journal of Music Education 31(2): 157177.

Kingsbury H (1988) Music, talent, and performance. A conservatory cultural system. Philadelphia: Temple University Press.

Korczynski, M (2003) Communities of coping: Collective emotional labour in service work. Organization 10(1): 55-79.

Krims A (2007) Music and urban geography. New York, London: Routledge.

Lave J and Wenger E (1991) Situated learning. Legitimate peripheral participation. Cambridge: Cambridge University Press.

Lea MR (2005) 'Communities of practice’ in higher education: Useful heuristic or educational model? In Barton D and Tusting K (eds) Beyond communities of practice. Language, power, and social context. Cambridge: Cambridge University Press, 180-197. MacGregor N (2014) Germany: Memories of a nation. London: Penguin Random House. Manturzewska M (1990) A biographical study of the life-span development of professional musicians. Psychology of Music 18(2): 112-139.

McPhail GJ (2010) Crossing boundaries: Sharing concepts of music teaching from classroom to studio. Music Education Research 12(1): 33-45.

Mills, J (2004a) Conservatoire students as instrumental teachers. Bulletin of the Council for Research in Music Education 161/162: 145-153.

Mills J (2004b) Working in music: The conservatoire professor. British Journal of Music Education 21(2): 179-198.

Mills J (2006) Performing and teaching: The beliefs and experience of music students as instrumental teachers. Psychology of Music 34(3): 372-390.

Mills J and Smith J (2003) Teachers' beliefs about effective instrumental teaching in schools and higher education. British Journal of Music Education 20(1): 5-27 
Nerland M (2001) Discourses and practices of instrumental teaching. In: Second International Research in Music Education Conference, University of Exeter, England, April 2001.

Nerland M (2007) One-to-one teaching as cultural practice: Two case studies from an academy of music. Music Education Research 9(3): 399-416.

Nerland M and Hanken IM (2002) Academies of music as arenas for education: Some reflections on the institutional construction of teacher-student relationships. In Hanken IM, Nielsen SG and Nerland M (eds) Research in and for higher education. Oslo: Norges musikkhøgskole, 167-186.

Nerland M and Hanken IM (2004) Apprenticeship in late modernity: Trust as a critical but challenged dimension in teacher-student relationships. In Professionalism, Trust and Competence conference, Oslo University College, Norway, June 2004.

Nettl B (1995) Heartland excursions: Ethnomusicological reflections on schools of music. Urbana and Chicago: University of Illinois.

Nielsen KN (1999) Learning at the academy of music as socially situated. Risskov: Psykologisk Intitut, Aarhus Universitet.

Nielsen K (2006) Apprenticeship at the academy of music. International Journal of Education and the Arts 7(4) http://ijea.asu.edu.

Persson R (1994) Control before shape. On mastering the clarinet: A case study on commonsense teaching. British Journal of Music Education 11(3): 223-238.

Presland C (2005) Conservatoire student and instrumental professor: The student perspective on a complex relationship. British Journal of Music Education 22(3): 237-248.

Purser D (2005) Performers as teachers: Exploring the teaching approaches of instrumental teachers in conservatoires. British Journal of Music Education 22(3): 287-298.

Reinhert K (2017) Private instruction the way of the dodo? Association for Popular Music Education. https://apmepopblog.wordpress.com/2017/06/01/private-instruction-the-wayof-the-dodo/ (accessed 26 June 2017).

Renshaw P (2002) Remaking the Conservatoire agenda. In CONNECTing conference, Queensland Conservatorium of Music, April 2002. Available at: http://musicinaustralia.org.au/index.php?title=remaking_the_conservatorium_agenda (accessed 6 March 2017).

Reynolds AM and Beitler NS (2007) Reflective practice in a middle-school instrumental setting. Bulletin of the Council for Research in Music Education 173: 55-69.

Rogers J (2016) Coaching skills. $4^{\text {th }}$ edn. Maidenhead: Open University Press. 
Schön DA (1987) Educating the reflective practitioner. Toward a new design for teaching and learning in the professions. San Francisco, London: Jossey-Bass.

Shulman L (2005) Signature pedagogies in the professions. Daedalus 134: 52-59.

Spencer SJ (2015) Musicians at the margins: a case study of the role of instrumental music teachers in a university music department. Doctor of Education thesis, University of Wolverhampton.

Tight M (2015) Theory application in higher education research: the case of communities of practice. European Journal of Higher Education 5(2): 111-126.

Triantafyllaki A (2010) "Workplace landscapes” and the construction of performance teachers' identity: The case of advanced music training institutions in Greece. British Journal of Music Education 27(2): 185-201.

Uszler M (1992) Research on the teaching of keyboard music. In Colwell R (ed.) Handbook of research on music teaching and learning. New York: Schirmer Books, 584-593.

Vescio V, Ross D and Adams A (2008) A review of research on the impact of professional learning communities on teaching practice and student learning. Teaching and Teacher Education 24: 80-91.

Wenger E (1998) Communities of practice: Learning, meaning, and identity. Cambridge: Cambridge University Press.

West T and Rostvall A-L (2003) A study of interaction and learning in instrumental teaching. International Journal of Music Education 40: 16-29.

Weston D (2017a) The place of practice in tertiary popular music studies: An epistemology. Journal of Popular Music Education 1(1): 101-116.

Weston D (2017b) Personal communication, 20 June.

Wright DCH (2005) The South Kensington music schools and the development of the British conservatoire in the late nineteenth century. Journal of the Royal Musical Association 130(2): 236-282.

Young V, Burwell K and Pickup D (2003) Areas of study and teaching strategies in instrumental teaching: A case study research project. Music Education Research 5(2): 139-155.

Zelm G van (2013) From competitors to colleagues: The experience of devising a peerlearning environment in a vocal department. In Westerlund $\mathrm{H}$ and Gaunt $\mathrm{H}$ (eds) Collaborative learning in higher music education: Why what and how? Aldershot: Ashgate, 179-185. 